\title{
Increasing Grid Integration of Wind Energy by using Ampacity Techniques
}

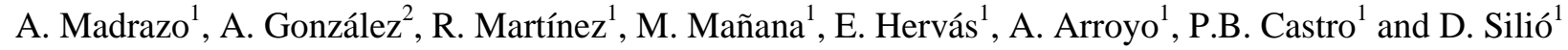 \\ ${ }^{1}$ Department of Electrical and Energy Engineering \\ University of Cantabria \\ Avda. Los Castros s/n, 39005 Santander (Spain) \\ Phone number:+0034 942 201378, e-mail: mananam@unican.es \\ ${ }^{2}$ E.On Distribución, S.L. \\ C/ Real Consulado, s/n (Pol. Candina) \\ 39011 SANTANDER \\ Phone number: +0034 942246000 (ext. 2475), e-mail: antonio.gonzalez@eon.com
}

\begin{abstract}
.
The grid integration of renewable energy, particularly in Spain, supposes an important problem to deal with for Distributor System Operators (DSO). Most of the times Wind Energy Farms are located in places that are far away from the transmission networks so they have to be integrated into distribution networks that are frequently operating close to their static rate. Current regulations make almost impossible to build new overhead lines so the increase of the capacity of the existing lines is a new target for the DSO. This paper is devoted to the analysis of a new methodology and monitoring system that have been developed to overcome the existing static rates by moving the operation point of the overhead lines close to their dynamic rate. This new rate is computed by using both the IEEE and CIGRÉ algorithms and a local weather forecast. The obtained results show that this approach can increase the capacity of the lines in a significant percentage.
\end{abstract}

\section{Key words}

Wind Energy, Ampacity, Grid Integration, monitoring system.

\section{Introduction}

The increasing number of renewable generation facilities, especially those based on wind energy, greatly affects the operation of the distribution networks, making them more complex to operate. In this scenario, the need to increase the capacity of the overhead lines is a major issue in order to prevent contingencies and to achieve good grid integration avoiding generation restrictions. As it is not possible to build new lines due to both environmental and governmental restrictions, it is compulsory to define new suitable methods that allow to increase the capacity of the existing infrastructure. Two possible solutions are: (i) repowering the existing lines by increasing the rated voltage and (ii) monitoring the overhead lines which is the approach followed in this article.
The aim of monitoring a line is to determine the real time ampacity by computing the maximum current that the line can carry depending on the weather conditions and the maximum conductor temperature. Furthermore, conductor temperature is monitored in order to know the status of the line in real time. If the operator is able to know the ampacity, the weather forecast and the real time current, it will be able to operate closer to the limit, maintaining a high level of security. The key point in this approach is to get an accurate weather forecast that can be used in the ampacity prediction, so the operator can make a reliable planning in advance.

The monitoring of conductor temperature can be made directly, with a sensor placed directly over the conductor or indirectly, using strength and/or inclination sensors.

The ampacity computation is well defined in standards such as IEEE and CIGRÉ. These standards are based on the same thermal balance but the terms are computed using different approaches. The inputs of these standards are the weather conditions (ambient temperature, wind speed, wind direction, solar radiation, etc.) and conductor characteristics (diameter, electric resistance, maximum temperature, etc.). This paper deals with the computation of not only real-time measured data but also next future forecast data.

\section{Ampacity}

In this research work, the algorithm used has been CIGRÉ. It is based on the following thermal balance in steady state:

$$
\begin{aligned}
& \text { HEAT GAIN = HEAT LOSS } \\
& \mathrm{P}_{\mathrm{j}}+\mathrm{P}_{\mathrm{M}}+\mathrm{P}_{\mathrm{s}}+\mathrm{P}_{\mathrm{i}}=\mathrm{P}_{\mathrm{c}}+\mathrm{P}_{\mathrm{r}}+\mathrm{P}_{\mathrm{w}}
\end{aligned}
$$


Where,

$$
\begin{aligned}
& \mathrm{P}_{\mathrm{j}}=\text { Joule heating }(\mathrm{W} / \mathrm{m}) \\
& \mathrm{P}_{\mathrm{M}}=\text { Magnetic heating }(\mathrm{W} / \mathrm{m}) \\
& \mathrm{P}_{\mathrm{s}}=\text { Solar heating }(\mathrm{W} / \mathrm{m}) \\
& \mathrm{P}_{\mathrm{i}}=\text { Corona heating }(\mathrm{W} / \mathrm{m}) \\
& \mathrm{P}_{\mathrm{c}}=\text { Convective cooling }(\mathrm{W} / \mathrm{m}) \\
& \mathrm{P}_{\mathrm{r}}=\text { Radiative cooling }(\mathrm{W} / \mathrm{m}) \\
& \mathrm{P}_{\mathrm{w}}=\text { Evaporative cooling }(\mathrm{W} / \mathrm{m})
\end{aligned}
$$

In a first approach, only $\mathrm{P}_{\mathrm{j}}, \mathrm{P}_{\mathrm{s}}, \mathrm{P}_{\mathrm{c}}$ and $\mathrm{P}_{\mathrm{r}}$ are taken into account. CIGRÉ define each term:

\section{JOULE HEATING}

$$
P_{j}=I^{2} \cdot R_{a c}\left[1+\alpha\left(T_{c}-20\right)\right]
$$

Where,

$\mathrm{R}_{\mathrm{ac}}=$ a.c resistance $(\Omega)$

$\alpha=$ Temperature coefficient of resistance per degree $\left(1 /{ }^{\circ} \mathrm{C}\right)$ $\mathrm{T}_{\mathrm{c}}=$ Conductor temperature $\left({ }^{\circ} \mathrm{C}\right)$

\section{$\underline{\text { SOLAR HEATING }}$}

In this paper, a simplification has been performed to take into account only direct radiation (data obtained from the weather station). It has to be taken into account that indirect radiation can be up to $50 \%$ of the total radiation so the value computed in eq. (3) can be considered as an underestimation.

$$
\mathrm{P}_{\mathrm{s}}=\delta \cdot \mathrm{D}\left[\mathrm{I}_{\mathrm{D}} \cdot(\sin \eta)\right]
$$

Where,

$\delta=$ Conductor absorptivity

$\mathrm{D}=$ Conductor diameter $(\mathrm{m})$

$\mathrm{I}_{\mathrm{D}}=$ Solar radiation from pyranometer $\left(\mathrm{W} / \mathrm{m}^{2}\right)$

$\eta=$ Angle of the solar beam with reference to the axis of the conductor $\left(^{\circ}\right)$

\section{CONVECTIVE COOLING}

$$
\mathrm{P}_{\mathrm{c}}=\pi \cdot \lambda_{\mathrm{f}}\left(\mathrm{T}_{\mathrm{c}}-\mathrm{T}_{\mathrm{a}}\right) \mathrm{Nu}
$$

Where,

$\lambda_{\mathrm{f}}=$ Thermal conductivity of air $\left(\mathrm{W} / \mathrm{m}^{\circ} \mathrm{C}\right)$

$\mathrm{T}_{\mathrm{c}}=$ Conductor temperature $\left({ }^{\circ} \mathrm{C}\right)$

$\mathrm{T}_{\mathrm{a}}=$ Ambient temperature $\left({ }^{\circ} \mathrm{C}\right)$

$\mathrm{Nu}=$ Nusselt number

\section{RADIATIVE COOLING}

$$
P_{r}=\pi . \text { D. E. } \sigma_{B} \cdot\left[\left(T_{c}+273\right)^{4}-\left(T_{a}+273\right)^{4}\right]
$$

Where,

$$
\mathrm{D}=\text { Conductor diameter }(\mathrm{m})
$$

$\varepsilon=$ Conductor emissivity

$\sigma_{\mathrm{B}}=$ Stefan-Boltzmann coefficient

$\mathrm{T}_{\mathrm{c}}=$ Conductor temperature $\left({ }^{\circ} \mathrm{C}\right)$

$\mathrm{T}_{\mathrm{a}}=$ Ambient temperature $\left({ }^{\circ} \mathrm{C}\right)$

Finally, the ampacity can be computed substituting eq. 25 in eq. 1 ,

$$
\mathbf{I}=\sqrt{\frac{\mathbf{P}_{\mathbf{c}}+\mathbf{P}_{\mathbf{r}}-\mathbf{P}_{\mathbf{s}}}{\mathbf{R}\left(\mathbf{T}_{\mathbf{c}}\right)}}
$$

A sensitivity analysis has been made in order to gain a good knowledge regarding each meteorological factor in the ampacity calculation. Figure 1 shows the dependence of the cable temperature with the independent variables solar radiation, current, wind speed and ambient temperature for the cable under study.

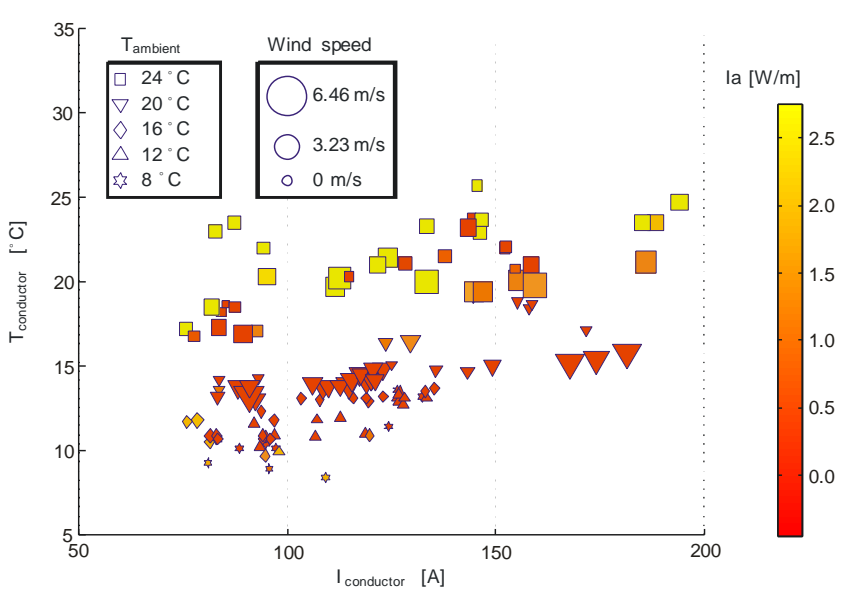

Fig. 1. Sensitivity analysis of meteorological data.

Another way to measure the temperature of the conductor in an indirect way is by measuring the strength and slope of the conductor.

From a qualitative point of view, each term in eq. 1 has a different contribution to the thermal balance. For a LA110 conductor, the quantitative values are summarized in Fig. 2 and 3 for two different operating conditions.

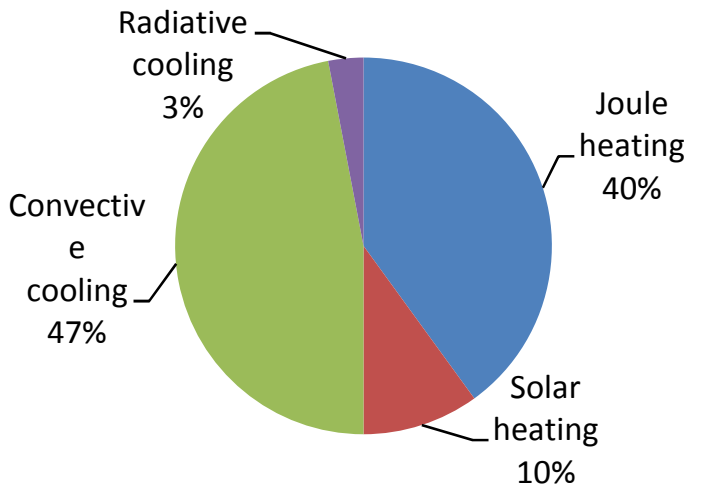

Fig. 2. Thermal balance in a LA-110 for a conductor operating at $200 \mathrm{~A}, 15^{\circ} \mathrm{C}, 3 \mathrm{~m} / \mathrm{s}$ and $400 \mathrm{~W} / \mathrm{m}^{2}$. 
Fig. 3 shows the thermal balance for a conductor operating with a current of $200 \mathrm{~A}$, an ambient temperature of $15^{\circ} \mathrm{C}$, a wind speed of $3 \mathrm{~m} / \mathrm{s}$ and an irradiance of $0 \mathrm{~W} / \mathrm{m}^{2}$.

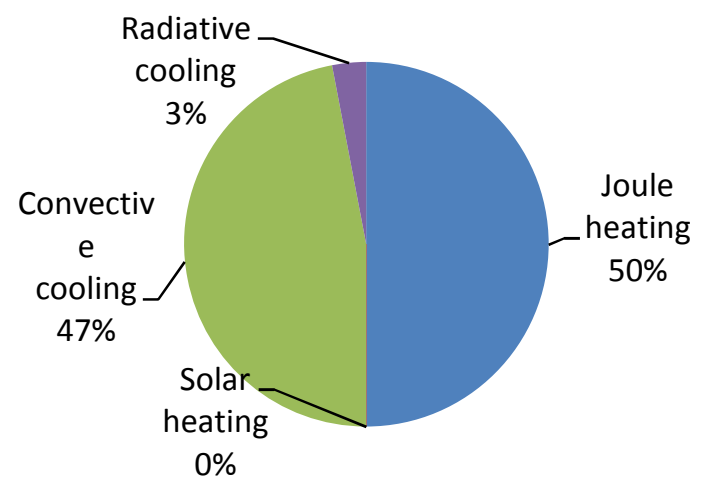

Fig. 3. Thermal balance in a LA-110 for a conductor operating at $200 \mathrm{~A}, 15^{\circ} \mathrm{C}, 3 \mathrm{~m} / \mathrm{s}$ and $0 \mathrm{~W} / \mathrm{m}^{2}$.

\section{Methodology}

The methodology proposed in this paper monitors weather conditions and superficial temperature in the cable and introduce them as inputs in the algorithm. The algorithm also includes data that is obtained by using weather forecast services.

All the data is recorded in a SQL server database so it is possible to generate SQL queries and other additional historical reports.

Firstly, meteorological data are obtained from weather station. These data are collected by a data logger and sent to a server by means of a modem with GPRS connection.

Furthermore, the temperature sensor (SMT) records and transmits the acquired data also using a GPRS modem.

Secondly, these data and the conductor physical characteristics are used by the algorithm. The computed ampacity is the output. This algorithm may be modified to get real time current through real time conductor temperature.

Finally, the DSO knows the maximum level of current and the real time current, so the lines can be operated closer to their limit. If weather forecast is accurate, the operator will be able to control the system in a predicted way. A solid historic data from weather station is required to get a reliable prediction.

Figure 4 shows the block diagram of the measurement and computation system used to obtain the ampacity.

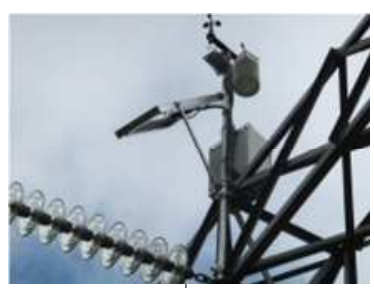

Weather station

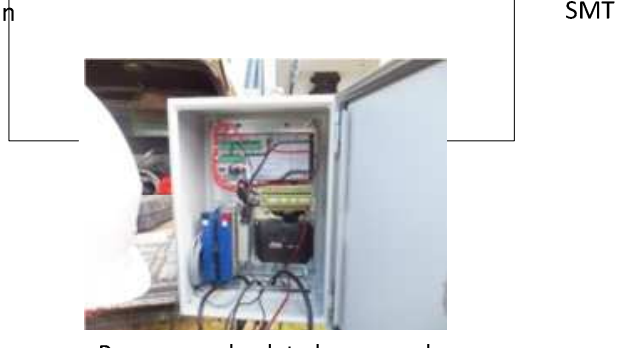

Power supply, data logger and

modem
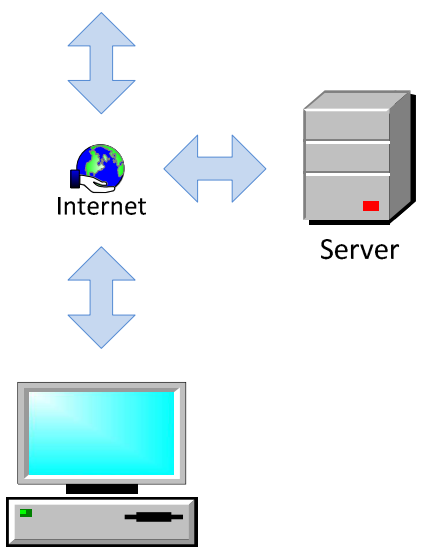

PC- CLIENT

Fig. 4. Ampacity monitoring system.

\section{Results}

Figure 5 shows the computed ampacity level with a sampling frequency of 1 sample each 4 minutes.

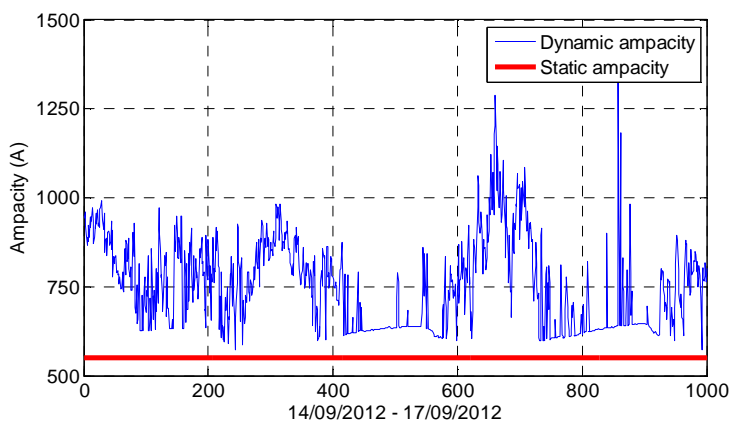

Fig. 5. Dynamic ampacity vs. static ampacity.

It can be observed that the real limit of the overhead line is, in a period of three days, always higher than the one chosen by the distribution company. In Figure 4 it is shown that the ampacity increase, for the case under study, is $15 \%$ in most of the cases and the average is $36.89 \%$. 
A real-time web server has been developed in order to show operating conditions and ampacity values. Fig. 6 shows a screenshot of the web server.

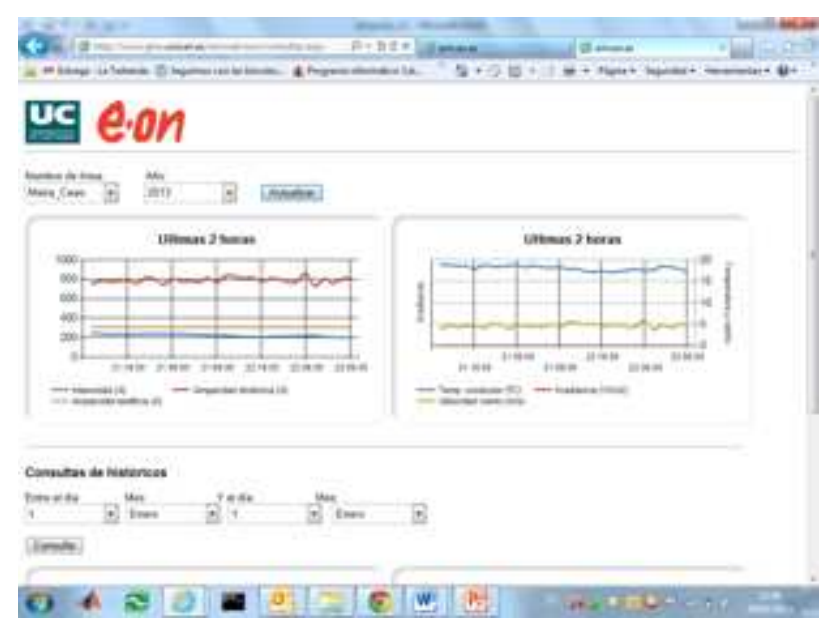

Fig. 6. Screenshot of the ampacity web server.

In addition, Fig. 7 shows the histogram of the increased ampacity.

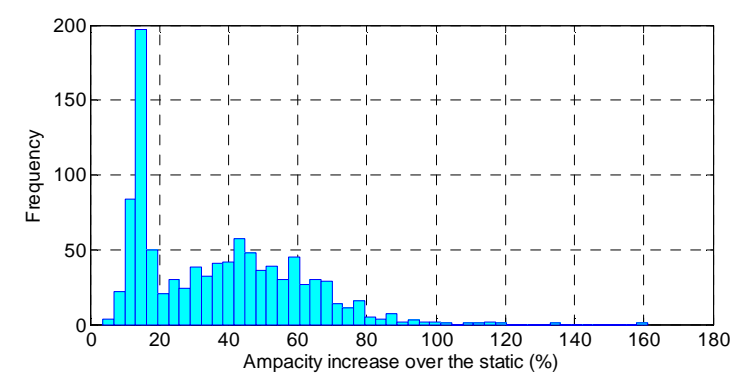

Fig. 7. Histogram increased ampacity.

\section{Conclusions}

The ampacity monitoring system allows DSO to operate closer to the real limit (ampacity) while maintaining an adequate security level of operation. This approach allows increasing the grid integration of wind energy. In a near future, the possibility of reliable weather forecast can provide an ampacity prediction that allows operators to perform a better planning.

As can be seen in the results, the level of ampacity is much greater than the static level fixed by the DSO. The most frequent ampacity increase percentage is around $15 \%$ and the average is $36.9 \%$. This would mean a large increase in the capacity of the monitored overhead line and therefore the grid integration of more wind energy.

\section{Acknowledgement}

This work was supported by the Spanish Government under the R+D initiative INNPACTO with reference IPT2011-1447-920000.

\section{References}

[1] IEEE Standard for Calculating the CurrentTemperature of Bare Overhead Conductors, IEEE Std 738-2006 (Revision of IEEE Std 738-1993).

[2] Mathematical Model for Evaluation of Conductor Temperature in The Steady (or Quasi-Steady) State (Normal Operation), CIGRE, ELECTRA No. 144, Oct. 1992, pp. 109-115.

[3] H.-J. DRÄGER, D. HUSSELS, R. PUFFER. Development and Implementation of a MonitoringSystem to Increase the Capacity of Overhead Lines. E.ON Netz GmbH. CIGRÉ 2008.

[4] K. KOPSIDAS AND S.M. ROWLAND. Evaluating opportunities for increasing power capacity of existing overhead line systems. Generation, Transmission Distribution, IET, 5(1):1-10, Jan. 2011.

[5] I. ALBIZU, E. FERNANDEZ, A.J. MAZON, AND J. BENGOECHEA. Hardware and software architecture for overhead line rating monitoring. In PowerTech, 2011 IEEE Trondheim, pages 1-6, June 2011. 